\title{
'Fun and Freedom'? Kaupapa Māori Approaches in the 48 Hour Film Competition
}

\author{
O. Ripeka Mercier and Challen Wilson ${ }^{\bullet}$
}

\begin{abstract}
48-Hour Film Competitions give people with a range of film-making experience a forum where their film can be made and screened in a short time in a sport-like arena (Mercier 2014), and the competition supports a wide range of motivations for participating (Mercier and Wilson 2013). While some of the films produced in this contest are worthy of analysis, our research is more concerned with the experiences of film-makers in this forum. As two Māori 48 Hour film-makers ourselves, we applied kaupapa Māori research principles to our interviews and audio commentaries with Aotearoa New Zealand competition participants. This article describes our motivation, rationale and methodology for exploring peoples' experiences in the competition and shares responses from nine participants who identify as Māori, regarding their own and their teams' 'kaupapa Māori' ways of working within the competition weekend. Our methodology as participantobservers encouraged frank exchanges regarding the challenges from the largely mainstream culture of the competition. Nonetheless we found that participants exhibited autonomy over their goals, process and product during the weekend and the freedom to exhibit not only their Māoritanga, but 'syncretic cultural practices' (Smith 2012, 44) that liberate and enable practictioners to retain a playful attitude towards the competition.
\end{abstract}

\section{Introduction}

You never have that amount of fun and freedom in any other filmmaking environment. (Taika Waititi in Russell 2012)

The 48 Hour Furious Filmmaking competition ${ }^{1}$ (hereinafter 'the 48') gives entrants two days to write, shoot and cut a 7-minute short film (revised to 5 minutes in 2016). Other constraints, including a prop, a named character and a line of dialogue, ensure competitors produce their film within the designated weekend. Stage and overall winners

O. Ripeka Mercier is Senior Lecturer in Te Kawa a Māui (School of Māori Studies) at Victoria University of Wellington. Challen Wilson is Strategic Broker, Kaipātiki Local Board, Auckland Council and Integrated Communications Consultant, The Sisters Consultancy. 
are selected through tournament-style heats, finals in each of several regions, then a Grand National Final and screenings on freeview television of the finalists' films. 'The 48' has become a significant and so far enduring feature of Aotearoa New Zealand's film landscape. A model imported by Ant Timpson from the United States (and now globally franchised) as the '48 Hour Film Project', the initiative has grown in Aotearoa New Zealand's metaphorical soil to produce thousands of locally flavoured films. Although these films are of uneven quality, they can nonetheless be seen as an historical record, giving insight into a group's process and creative endeavour.

Professionals who have been involved in 'the 48' rate it highly, as allowing 'people to try things out, fail and succeed in equal measure, and watch their film on a big screen.' (Jarrod Holt in Russell 2012). This freedom from budgetary restraint prioritises fun and allows risks to be taken: 'worst case scenario, you've had a fun weekend, not lost a studio millions of dollars' (Tim Batt in Russell 2012). However, most participants are amateurs, newcomers or even last-minute call-ups, and their experiences and motivations in the competition receive negligible attention.

In our research on 'the 48' we sought out and interviewed people with a range of filmmaking experience to address this gap, and our first article explored contestants' motivations for entering (Mercier and Wilson 2013). We found that in addition to the often cited (and indeed evident in the Holt and Waititi quotes above) play, build, practice and audience goals, competitors found opportunity in 'the 48' to practice or voice particular political motivations, such as interrogating social norms, voicing a political concern, representing a minority position or consciously doing something different from previous 48 Hour films' (Mercier and Wilson 2013, 69). The contest's openness allows practices and products that push back against particular status quos, but the question of how Māori political aspirations are realised was not core to our previous article, which dealt with a broader 'ethnic' cross-section of participants.

To examine this more specific Aotearoa New Zealand element of limited-time filmmaking we devised and used a kaupapa Māori methodology to explore our participants' experiences. In doing so we had to situate our research at an intersection of disciplines. This was a challenge, as methodological studies in film studies in relation to their reception from audiences are rare (Reinhard and Olson 2016; Barker and Austin 2000) and in relation to their makers, rarer still. This led us to perceive film scholars as traditionally eschewing contact with the maker of the film they are critiquing, for instance, viewing with suspicion DVD special features such as recorded interviews and audio commentaries (Grant 2008). That approach seems at odds with our desire to explore the liminal space between film and social studies. One of our overarching questions in this space is around how 'the 48' 'collapses the boundary between spectator and spectacle in a way that no other form of screen fiction claims to do' (Mercier and Wilson 2013, 73). Important to an examination of the interface between the spectacle and the spectator, in the case of 'the 48', is the approach to and engagement with the filmmaker, and exploring how a film-maker engages with their film. With this carefully 
selected cohort, it is appropriate and needful to justify selection, report on how we implemented our methodology, and speculate on the data that emerges as a result. A 'representative' sample surfaces a broad set of issues. Our sample, in which a third of our participants were Māori, was deliberately chosen to give volume to voices typically found on the margins. This is where a kaupapa Māori method and analysis is critically important.

Kaupapa Māori in relation to film has been discussed in numerous places (Barclay 1990, Barclay 1992, Mita 1992, Waititi 2008, Wilson 2013, Stephens 2014) and these were influential in our research. However, the key aims we held in mind came mostly from kaupapa Māori's education- and health-based scholars:

- To reposition Māori at the centre, taking Māoriness as normal (Smith 1995);

- To produce work by Māori, with Māori, for Māori (Barclay 1992);

- That we as Māori drive the research agenda and outcome: thus deciding on the questions and who the participants will be (Smith 2012);

- To expand the limits of what is considered Māori-related research (Cunningham 2000).

We adopt these principles in our research to give moment to the voices of Māori participants, and to explore what a kaupapa Māori approach can add and reveal to the scape of film literature. Did our participants experience that 'fun and freedom' that Waititi argues no other film-making forum can provide? What do Māori participants' approaches to film-making look like? An important part of kaupapa Māori methods is an emic viewpoint, so we now discuss ourselves as Māori participant-observers in this research, revealing intersections of our selves with the competition and with other participants.

In 2004, 9 finalists from the 48 Hour Film Competition screened on C4, a free to air music channel with about $80 \%$ broadcast coverage across New Zealand. I (Ocean) still remember clearly the winning entry, which stood out for two reasons. First, it came from Wellington, rather subverting expectations that someone from the delivery place of 'the 48', Auckland, would win. Second, it was made by and featured Māori comedian, director, actor Taika Waititi. Waititi had just made 2 Cars, 1 Night (2004), a short film that would see the director nominated for an Academy Award in 2005. His entry Heinous Crime featured himself playing multiple characters, a technique that would become a motif in his other 48 Hour works in 2005, 2006, 2007 and 2008. Transitions between these different characters in Heinous Crime were technically underwhelming, hilarious in and of itself. The seeming achievability of this standard of filmmaking inspired me to enter. I subsequently assembled team and competed in 2006 and 2007. Our first film screened alongside 10 or so others in one of eight heats. I was struck by the audience reaction to Faery Disenchanted, one of the other films in our heat. The key character, Robin Slade, was a motivational therapist, and when he used te reo Māori terms such as 'kia kaha' (be strong) and 'ka pai' (good), the audience erupted with laughter. Another film, Gunther and $M e$, got a similarly positive reaction from the audience, but I was left cringing that the 
character trait chosen to portray a gangster was the use of a faux Māori accent. This left me wondering about this 'unrestraint' (Mercier 2014) in the indulgence of cultural biases and compelled me to further examine the culture of the competition. To aid me in this, I was joined by another Māori 48 Hour Filmmaker as a research assistant, my co-author Challen Wilson.

Initially, the reason I (Challen) got involved was as a researcher on a Victoria University of Wellington Summer Internship, working with Ocean. Our dual interest in 'the 48', specifically the film-makers, connected us. I was studying film and theatre, and I felt the academic field of film studies was dominated by particular styles of film structure analysis and critique, which did not encompass all that I wanted to investigate. Ocean was applying different research methods and analyses that were a mix of film, story, culture, community and process.

It was an advantage that I had contributed to a film called Tyrique Don't Believe in Monsters, which was made in 'the 48' in 2006. So I had experience, knowledge and skill to contribute to the research and I was particularly interested in how communities of 48 Hour film-makers worked together. The second point that interested me was how to read film from the lens of kaupapa Māori research methods.

It is useful for us to think of a kaupapa Māori 'lens' as a viewpoint that invites particular kinds of questions, to do with identity as Māori, adaptation and resilience in a colonial context (Mita 1992) and many other concerns. For instance, authors who have explored Taika Waititi's Boy (2010) from a Māori-centred viewpoint ask a range of questions: how are Māori masculinities represented? (Hokowhitu 2012) Can a spectator feel the mauri and/or wairua of characters in a film? (Wilson 2013) and can 'weirdo' characters be understood in terms of a post-colonial taniwha? (Kavka and Turner 2012).

But perhaps the most important consideration here, and one that connects to Taika's statement about 'fun and freedom', is the global expectation for Indigenous productions to have an 'arthouse-ready anthropological edge' (Smith quoting Variety reviewer de Bruges in 2012, 40). 'While Indigenous practitioners strive to articulate their visions of the world, audiences, film critics and academics must equally strive to shake the frameworks of orthodox interpretations surrounding things Indigenous' $(2012,44)$. Here, we explore how recognising and valuing kaupapa Māori on the one hand, but also putting aside orthodox expectations of Māori and kaupapa Māori practices, allows us to freely explore the practices of a group of Māori film-makers.

\section{Methodology}

This article focuses on the experiences of Māori in the competition. As two Māori participant-observers in the community of Māori 48 Hour Film-makers we felt a rapport with film-makers in regard to their experiences in and with the competition, and entrusted now to share those. In the description of the methodological process that 
follows, we outline our pre-production, production and post-production stages leading to this article.

\section{Pre-production}

We sought and gained ethics approval from the Victoria University of Wellington Human Ethics Committee for interviews and commentaries done on a non-confidential, attributed basis. We felt attribution was important so that the film-maker retain a sense of mana (sovereignty) over, ownership of and accountability for their contribution.

From our own involvement in the competition, we had certain participants in mind for involving in the study, for instance, friends who'd taken part. We found other participants through watching films on the 48 Hours DVD compilations and the 'V48' (as it was known then) online Screening Room. We selected films whose stories featured cross-cultural interaction, whose cast displayed cultural diversity, or whose cast and/or crew had a significant Māori and Pasifika presence. A longlist of teams to approach was prepared from this screening process. We found film-makers' names from film credits, and for most professionals and semi-professionals we were able to find email contacts online. From email contacts we sent invitations and interviewed those who responded. We also contacted a number of participants through Facebook, three of whom we interviewed. Our information sheets for all participants included a short mihi (greeting) in te reo Māori, and Ocean's iwi affiliation was provided with her contact details, along with the title of the project, Screen(ed) Culture in the 48 Hour Film Competition. This identification and positioning was intended to provoke potential participants to reflect on our and their subjectivities in relation to the research.

\section{Production}

We prepared 14 interview questions on a number of themes, including team process, competition constraints, film and cultural influences, and participant perceptions of notions like DIY film, guerrilla film and sport film. Questions were not asked in order, and most interviews flowed like a conversation. As non-professional film-makers we were unintimidating to our non-professional participants. When we shared our own experiences that was appreciated, affirmed and sometimes triggered other responses. Throughout, we could demonstrate an insider's interest in and knowledge of the participant's production and the challenges inherent in getting it to the screen. We also gained empathetic responses related to our position on the margins of the typical 48 demographic - as evidenced through verbal affirmations such as 'I guess you guys would know' (Damon Fepulea'i). A shared understanding of te reo meant that terms like tikanga, kaupapa, whanaungatanga, paepae, mamae, kōrero were used, correctly pronounced and understood.

Audio commentaries were recorded in order to explore the relationship of the film-maker with the people and ideas depicted in their film. We expected that re-watching the film would trigger engagement with more specific moments over 'the 48' weekend than generalised interview questions could. We piloted the process by having Ocean conduct an interview with Challen, of team GomI. After the interview Ocean set Challen up on a 
MacBook Pro to record an audio commentary for Tyrique. This modelled the process for Challen, who the same day put that into practice and interviewed Ocean and teammate Tyrone MacKintosh from Oh Silhouetta, and oversaw the recording of commentaries on their two films: Cold Sunshine and (Kill!).

Our first interviews were with participants from Wellington conducted in December 2009 and January 2010. We travelled in January 2010 to interview participants in Auckland and Gisborne. Ocean interviewed participants from Christchurch and Dunedin in May 2010. Six of our interviews were with 2 team participants, and the remaining 14 were with individuals, for a total of 26 interviewees. 9 participants identified as Māori, 2 as Pasifika, and 15 as Pākehā. Table 1 shows the list of Māori and Pasifika participants whose contributions inform this article. Some team members were interviewed separately, but in all cases we were able to conduct commentaries with both team members together. Two others gave commentaries with a teammate, but not an interview.

\begin{tabular}{|c|c|c|c|c|}
\hline Team & Interviewee & Film & Year & City \\
\hline Goml & Challen Wilson, Am & $\begin{array}{l}\text { Tyrique Don't } \\
\text { Believe in Monsters }\end{array}$ & 2006 & Wellington \\
\hline \multirow[t]{2}{*}{ Oh Silhouetta } & \multirow{2}{*}{$\begin{array}{l}\text { Rānui Taiapa, Am } \\
\text { Tyrone MacKintosh, } \\
\text { Am }\end{array}$} & Cold Sunshine & 2006 & \multirow[t]{2}{*}{ Wellington } \\
\hline & & $(\text { Kill! })^{4}$ & 2007 & \\
\hline $\begin{array}{l}\text { The Goat Embryo } \\
\text { Project }\end{array}$ & $\begin{array}{l}\text { Alice Te Punga } \\
\text { Somerville, New } \\
\text { Terese McLeod, Am }\end{array}$ & Manimal Planet & 2008 & Wellington \\
\hline \multirow[t]{2}{*}{ Liquid Chicken } & \multirow[t]{2}{*}{ Grant Roa, Pro } & Love Cycle & 2008 & \multirow[t]{2}{*}{ Wellington } \\
\hline & & No Warrant & 2009 & \\
\hline $\begin{array}{l}\text { Kairangi } \\
\text { Productions }\end{array}$ & $\begin{array}{l}\text { Richard Tuhaka, Am } \\
\text { Pele Takurua, New }\end{array}$ & One Man's War & 2007 & Gisborne \\
\hline Sink or Swimee & Rīria Hōtere, Pro & Kai a te Kurī & 2005 & Auckland \\
\hline \multirow[t]{2}{*}{ Goodfellas } & \multirow{2}{*}{$\begin{array}{l}\text { Damon Fepulea'i, Pro } \\
\text { Henry Tuipe'a, Pro }\end{array}$} & In Search of Bigfoot & 2008 & \multirow[t]{2}{*}{ Auckland } \\
\hline & & Fanatics & 2009 & \\
\hline
\end{tabular}

Table 1: team names of Māori and Pasifika interviewees, their film names, year/s entered and city of entry. Abbreviations following each name give participants' engagement (at the time) in the film industry: New = new to film-making, $\mathrm{Am}=$ experience in film-making, Pro = paid experience in film-making (part-time or fulltime).

In order for the recording of audio commentaries to be as integrated with our interview session as possible, we recorded using the podcast capability in GarageBand which allows one to view the film in a window, while the MacBook captures ambient audio. Both Ocean 
and Challen were present for most of the interviews and commentaries, and to maintain communication with participants and their film we did not use a studio or headphones. This meant that the film's audio volume had to be turned down low, in order to capture the commentator audibly above the film audio playing in the background. Ocean and Challen took turns to conduct interviews, and then typically Ocean would transfer electronic data to USB memory sticks, while Challen prepared kai (food). Reciprocating for the time participants had given to the project happened in different ways: including valuing participants' films and introducing them to an innovative way to reflect on their films. Kai was also an important way to show we valued the connection: in some cases kai consisted of a full meal - a lunch of toasted sandwiches in one case, a dinner of takeaway curry in another - in others a cup of tea and snacks.

As an additional koha, we gave each participant a 2GB memory stick upon which to take their interview and their film with commentary. Technically, this required some organisation during the session and could not have been done without two of us working together. In most cases Ocean was able to preload a 'rip' of the participant's film/s into Garageband, but on a few occasions where the film was not published online or on the DVD the participant brought their own copy of it on CD, DVD or USB memory stick. On the one occasion we were unable to access a film, our participant recorded the commentary later and sent the file to us. We also sent electronic interview transcripts to each participant. We do not consider this a koha, especially as most researchers at this stage are expecting participants to read, make changes to their transcript and to approve it.

Each interview lasted anywhere from 40 minutes to 2 hours, and the commentary recording session took between 15 minutes and an hour, depending upon how many commentaries the participant/s chose to do. Generally, participants seem to enjoy both the interview and the commentary, the latter a new experience for most of them. When Challen and I joined the participant on their audio commentary we contributed from a shared understanding of the trials and tribulations of the weekend and difficulties of making a film in 48 Hours. To focus the scope of the article to things said in interviews, we present only a few quotes and observations from the commentaries.

\section{Post-production}

Interviews and commentaries were transcribed, loaded into and coded using the qualitative data analysis tool NVivo 9. In early 2012 the interviews were coded according to a set of about 40 recurring themes and analysis of the coded data identified which of the themes were most prevalent. As participant observers, we aim to strike a balance between practice and theory - to produce a paper that is relevant and accessible to practitioners as well as academics. As part of this we have maintained an interest in our participants work, through Facebook and YouTube, and we have emailed our research articles to our participants. 


\section{Kaupapa Māori Practices in 'the 48'}

Narratives here are presented with the question in mind: what 'freedoms' did the filmmakers we spoke to have in their process and how can we represent that diversity here? The following illustrates how our film-makers' practices can assume a Māori centre while drawing upon other influences. Participant reflections are organised in three sections below. Comments discussed under whakapapa explore how our participants relate their practice to contextual influences: whether these be other Māori, other film-makers, places or the wider social context. Comments discussed under kaupapa reveal specific kaupapa, motivations or goals that guided, led or drove participants through their 48 experiences. Comments organised under tikanga reveal the different specific practices that participants used in their mahi.

\section{Whakapapa}

Whakapapa is understood as a genealogy that connects all living beings, human and nonhuman. It has also been used to explore how knowledge is connected and how ideas and understanding come to be (Royal 1998). Thus, whakapapa is used to describe biologically living and non-living things. It literally means to place in layers. Understanding one's place within the layers requires an exploration and understanding of other layers, the context and one's place within it. Roberts and Wills (2002) state that to 'know' something is to locate it in time and space. Thus, here we use an expanded definition of whakapapa to act as a container for kōrero (narratives, talk) related to Who our participants are, and how that is expressed in their process or product.

\section{Māori Influences}

Although it wasn't any one participant's primary motivation for entering, most revealed a strong sense of connecting to a whakapapa of Māori storytelling, drawing inspiration from other Māori and aimed to emulate these Māori within their own filmmaking practices during 'the 48' weekend. On Waititi's entry Heinous Crime (2005) Rānui Taiapa shared: 'it was a really amazing film but it just felt so reachable, that standard, it felt like "Hey we can do that, we've got a lot of talent".' Grand National Winner Brown Peril (2006), featuring a Tongan badminton player, was an inspiration for Kairangi Productions and others. Pele Takurua notes that in terms of the 'genuine humour' in their own film, she found inspiration from the paepae (speaking arena at the marae):

When our papas are talking and they crack jokes and what not, it's the same humour, except they're doing it in a formal way. And when they get together, there's always something that they're cracking up about. (Pele Takurua)

Terese McLeod had done journalistic research into Ainsley Gardiner, Cliff Curtis and Taika Waititi for Kōkiri Paetae, and through those interactions had been particularly taken by Ainsley's 'Māori model of moviemaking'. Through the competition she had opportunity to try this model with her team:

So, we had a broad range as you can see in the film. There's Matiu who was about three at the time right up to our cousins who are in their fifties. So 
that was a nice whānau way to work. And as you know, making movies is a village thing. Takes a village to make a movie. And our people lend themselves naturally to that often, more than some of the non-Maori crews I've worked with, which hasn't been fun at times [laugh]. (Terese McLeod)

The whānau intergenerationality that comes through in the practice of Goat Embryo Project was a contrast to other teams Terese had worked with. Alice te Punga Somerville thinks this ideal was 'deeply related to it being a Māori project'.2 Alice and Rānui both had in mind Barry Barclay's ideas related to the camera: its power to control the representation, and its power to misbehave (1990). Pele's students from Te Kura a Rohe o Ũawa (Tolaga Bay Area School) were 'so much in awe of One Man's War' (2007) that it inspired some of them to put together team Te Kuranui and enter the competition, through which they made a film in te reo Māori.

Other Filmic Influences

A number of inspirations were acknowledged when we asked participants what were their influences in film. These included Spike Lee and his film The Huey P Newton Story (Lee, 2001), Taika Waititi and his short films, Jackie Chan and The Fearless Hyena (Chan, 1979), M Night Shyamalan and Unbreakable (2000), Mike Moore, Quentin Tarantino, Peter Jackson, Fran Walsh, Philippa Boyens and Lord of the Rings (Jackson, 2001-2003), and The Matrix (Wachowski, 1999). Some of these influences were quite obvious in the participants' films. For instance, in One Man's War (2007) the main protaganists end the film with a choreographed fight scene that incorporates elements of Hong Kong martial art film with a modern Tarantino-esque sensibility, presenting a locally iconic homage to the beloved martial arts flick. Other influences mentioned, such as Bamboozled (Lee, 2000), did not find explicit expression in the films, but nonetheless connect the filmmakers to a wider whakapapa of film practitioners. As Jo Smith notes, the hybridising of external and Māori influences 'gestures to the longer histories of syncretic cultural practices' (2012:44) and offers our participants freedom of expression (or not) of their Indigeneity in combination with other influences.

Place

Place was a consideration to most of our participants. Rānui wanted to share local places of meaning to her by committing them to film. An amateur participant, she volunteered that her first film was technically 'shocking'. However, in her audio commentary she pointed at locations familiar to her, such as the playground where 'I used to go to school', and the 'skody curtains' in 'my little flat in Kilbirnie'. The audio commentary revealed a canvas of personal nostalgia bleeding through her transparently laid and roughly sketched story. Richard Tuhaka and Pele staged their fight scene in the derelict freezing works at Waima and drenched their audio and visuals with 'Coastie Humour'. This was appreciated by Gisborne audiences: director Richard recounts 'when we showed our friends and family they were laughing so much' that they did not hear some of the jokes. Alice and Terese, of Te Atiawa (who hold mana whenua in Wellington) took their whānau team to Matiu/Somes Island to film. A barbeque was a central feature of the film and the 
weekend, performing an important role in fostering relationships between people and their lands. This in turn reconnected whānau / mana whenua to places that shape their people's identity.

\section{Aotearoa New Zealand Social Context}

We don't all really wanna spend a weekend feeling stupid, [laughs] yea we have lots of opportunities to do that as Māori but why would we want to do that on our weekends [laughs]. (Alice Te Punga Somerville)

'The 48' supports a diverse range of participant motivations (Mercier and Wilson 2013), but it is still a distinct cultural space that presents the usual challenges to Māori identity and cultural safety. But as Alice asks, do those wider societal burdens have to encroach upon a weekend that people have chosen and committed to? Can the microcosm of the team weekend provide enough 'fun and freedom' to outweigh the challenges of not being recognised in the wider setting of the competition? In what ways does kaupapa Māori contribute to that?

As one of her influences, Terese cited a legacy of social injustice and looked forward to ways to explore that story on film. But while she had entered 'the 48' seven times, she had not had creative control to try and address the issue through film. She and teammate Alice sought ways to explore a 'Māori model of filmmaking', even insomuch as the external restraints on the film produced during the weekend were not necessarily conducive to exploring these themes in the film itself. Alice, Terese and Riria Hōtere, from Sink or Swimee, were all cognisant of 'the 48 ' as a mainstream medium, and explicitly commented upon the 'whiteness' of the competition. Alice and Terese noted that guidance was needed for a teammate to recognise the degree of whiteness.

[Name withheld] didn't see this...but once we pointed it out to him, he was like, 'Oh I never really thought of that', just how white the rest of the films were. Like most of them, not all of them, but you notice the ones that have brownies in them.

Taking Pākehā as the norm in the news media has been argued to contribute to anti-Māori themes (Barnes et al 2012). A strong mainstream culture inside the competition may marginalise other cultural contributions and inhibit the ability of participants, organisers and judges to see other ways of telling stories, while simultaneously making Māori contributions really stand out. Touching on all of these points, regarding their entry in te reo Māori, Riria comments that 'we were like the wild card I spose'. Pākeha participants who explicitly recognised and commented upon a lack of cultural diversity were Jarrod Holt, of the downlowconcept and Steve Austin, judge for Christchurch. They see the importance of ethnic diversity and a range of ages in the film, and Steve and Tania Smith (judge for Gisborne) had discussed mechanisms to encourage greater diversity. At the time, participants still questioned the judges' ability to assess films with overt Māori themes. 
It's really unrepresentative in a whole lot of ways. In terms of age, in terms of socio-economic background, in terms of ethnicity and you see them physically when you're in the theatre. Its just hōhā...I don't know why Hone Kouka's not a judge or other people like that aye. These questions need to be asked. (Terese McLeod)

Although the challenge of monoculturalism from the wider social context are present in the arena of 'the 48', each team has the autonomy to claim its own space and time, define its own goals, and to define and be guided by its own rules even as those monocultural norms threatened to encroach upon the team unit.

Partly also I was aware that the main people who had the expertise were our two white boys, and I thought, 'Yea that's a little bit of a recipe for a bloody disaster right', [them] knowing everything and all these little brown people running around doing stuff and so I kind of wanted to upset that a little bit [laughs] like pull the rug out from under their feet and then go, 'Go editing, go camera-ing, do what you do but this is our project.' (Alice Te Punga Somerville)

The words 'our project' suggests that this was a whānau project on a kaupapa that all had agreed upon. Nonetheless here Alice revealed that effort was required to keep the prow of the waka pointed at the kaupapa. Much of that work would involve resituating whānau away from the margins, and the film-makers away from their assumed centre.

\section{Kaupapa}

By kaupapa, we mean the Why and What, or the goals and motivations that drive the participation and completion of a film during 'the 48' weekend. Kaupapa is not isolated from whakapapa. In fact, most of our participants talked about identity in concert with their aims: whether to stamp it in relation to the wider context of the competition, to claim and use te reo Māori, take cast and crew diversity as a normal thing or to foster identity growth through promoting whanaungatanga.

As discussed previously, 'the 48' attracts 'a dominant group, by and large' (Terese McLeod) and was wryly described as 'affirmative action for 20-something males' (Alice Te Punga Somerville). These perceptions of the milieu were made after the fact of participating in the competition. Alice wanting 'to pull the rug out from under their feet' speaks to upsetting traditional power imbalances, often wrought by intergenerationalised privilege. Rānui revealed in hindsight that with a small change her film could have 'questioned all of those film stereotypes, like male violence on female' and thus upset gender imbalances seen in films generally and 'the 48' more specifically. In conversation with Ocean about the satirical film that she'd felt misused te reo Māori, Riria agreed, but was quick to add that her key motivation was to make a film that satisfies its own imperatives, not just with a view to 'let's show the buggers'. 
Riria stated that she wanted to make te reo a normal aspect of the film. She felt like the target audience of her team Sink or Swimee's (a collection of artisans from production house Cinco Cine) film Kai a te Kurī (2005) was mainstream. But how that mainstream audience perceived the film was a source of anxiety for her.

I remember watching people when we went to the screening at the Civic Theatre in Auckland, I remember because we were sitting, there was a whole line of 'us' and then there was everyone else. And it felt a little bit like that when the film played. Gosh, we know this film inside out now, but everyone else is kinda like "whhaaatt". They were a bit taken aback by it not being in English. And I remember thinking, was that a good idea, and then I thought, actually, of course it is, this is exactly what we need to be doing with our reo is to be putting it out there and pushing it into these areas where it's not going to get seen otherwise. And that was really important to us. (Riria Hōtere)

'Having a lot of girls involved', especially behind screen, was important to Alice and Rānui. One Man's War (2007) was and continues to be unusual in that it presents its female, nonsexualised antagonist as normal. Terese noted how different and refreshing it was to see a diversity of race, gender and age on screen in her own movie ${ }^{2}$.

And so, for me I saw for the first time in 48, a really representative cast and crew unit, portrayed on film and behind film. So that was really refreshing to see for me, you know, seeing Māori faces on film, seeing the range of age cause usually you see sort of 20-somethings in these movies, so that was kinda cool. (Terese McLeod)

Another part of Goat Embryo Project's motivation for centering the weekend on the whānau was nothing to do with making a film, taking part in the 48 Hour weekend, or performing back to sexism and racism; but bringing members of the wider whānau together. They also wanted to involve, empower and upskill whānau, including themselves, in filmmaking. Pele Takurua stated a similar motivation for competitions she entered subsequent to Kairangi Productions, in which she mentored pupils at her school with moral support and advising the children on technical issues. Rānui wanted to give her teammate and main actor an outlet for his talents, a way to develop them and generate material for his showreel.

Riria's team were the first to submit a 48 entry in te reo, but she expressed delight to hear that Gisborne and other centres had produced te reo Māori films. She applauded the idea of a Māori 48 competition to support the growing community:

You see, I think that that's excellent. If we were the first ones to do it and there's other teams popping up then this could turn into a contest, like that. We could do our own contest, why not? (Rīria Hotere) 
For Riria the focus on kaupapa worked because everyone in the (all-Māori) cast and crew bought into the kaupapa. By contrast there were tensions brought into the Goat Embryo Project when one of the writers, worried about the time being taken for group mihimihi (greetings and introductions), took to leading the team in a non-collaborative, nonkaupapa way. The director and team's process in dealing with the arrogant behaviour was to acknowledge but then politely ignore the contribution. This reflects the whānau's trust in their director Alice, and her trust in them, and the tikanga and kaupapa operating through her team co-operating on the waka she was leading.

\section{Tikanga}

Our participants spoke of numerous aspects of their practice, or the How, that can connect to a whakapapa of kaupapa Māori filmmaking. We present here an eclectic but diverse selection of comment on technical aspects of filmmaking followed by a short discussion of te reo Māori and finally discuss how participants worked together.

Technical / Craft

How can we take that maverick yet fond friend of ours - the camera - into the Māori community and be confident it will behave with dignity? (Barclay 1990)

As a cameraperson in a documentary context, Rānui had explored how, in practice, to 'make the camera behave' with dignity. She saw herself (and camera) as subservient to what was going on around her, and tried to 'see' the way the community sees, not as an outsider.

[It's] making the camera obey the rules of the setting, so that if I'm in a village council meeting in Samoa for instance, then the camera is not stuck up on this pedestal it's at floor level with everybody else who's sitting around the room. The camera doesn't get to travel because people who are in the village council meeting don't get to walk around the room, and wander around the place. The camera's gotta behave. So it's gotta sit there with me and just look quietly, not be too intrusive about how it's looking. Not massive zooms into someone's eye or someone's teeth. And it's about trying not to disconnect pieces of the picture from other pieces. (Rānui Taiapa)

One aspect of Goat Embryo Project's process, Alice explains, is that like on the marae, the set was ruled by the kitchen. She said that the timekeeping of the chefs took pressure off her as a director, and encouraged a nurturing rhythm.

I mean there's a reason why the kitchen runs the show at a marae you know, it's not just because we're all naturally greedy people who love eating, although that's part of it, but it's about remembering that the really important thing is gathering together over food and you know, the kind of 
big picture around mahi that all kind of adds up to stuff... and I thought that was quite important to bring into our [process]. (Alice Te Punga Somerville)

Terese noted her role as producer felt different from her experiences producing for teams in prior competitions. She had to strike a fine balance between the whanaungatanga, connecting to place, fun, managing external relations (a reporter and cameraperson did a television news story on the team) and making a film in 48 Hours.

'cause the crowd we had wouldn't respond to quite commando style [laugh] operations. Being whānau they're likely to tell you, to say kao (no) [laughter]. So I had to have a casual approach to it, but I did have my eye on the time. But not in a sort of a 'banky' way of like making it unfun for people because that's when they buy out [laugh], when it stops being fun. (Terese McLeod)

Terese wanted to preserve the 'fun' of the weekend, and played a critical role as a producer to ensure contributors had 'freedom' of expression, within the constraints of the contest. As an actor, Grant Roa attributes his non-reliance on formal scripts to 'I'm from an oral culture, I don't do words on paper' and favoured a more improvisational approach. His main co-star on Love Cycle (2008) worked similarly, as he noted during his audio commentary, 'I don't know if any of this was actually scripted, within reason, 'cause Taungaroa [Emile] won't stick to a script either' (Grant Roa).

Pele and Richard, as set scouts and designers, and props organisers, commented on a 'can do' attitude on the East Coast that makes the best of the more limited locations, facilities and materials in a small place like Tolaga Bay. Richard and Pele cast themselves and embodied a balance that included a strong and unclichéd female character. As writers, Richard and Pele were keen for their 'Coastie humour' to be reflected off and heard from the screen. But their tikanga was to avoid sex and violence, and stated their humour was not at the expense of other cultures 'we were making fun of ourselves, you know' (Pele Takurua). Riria made the point that their team's writer made the English subtitles for Kai a te Kuri as funny as the te reo script. She noted that that takes a writer of rare talent and experience.

\section{Te Reo Māori}

Of our participants, Riria had the most to say on the use of te reo Māori. Her team saw te reo as intrinsic to the story. The reo was not sprinkled in, nor was the script a translation, the scripting of Kai a te Kurì in te reo reflected business as usual for the 'tight' crew at Sink or Swimee (aka Cino Cine). They perhaps epitomise an ideal of assuming Māori as the normal position to work from. Furthermore, she states that:

If they wanted me to translate something just so they could get some reo in there, nah. No, it's not a toy [laugh], it's a taonga. You don't just put it in there for no reason. (Riria Hōtere) 
Riria does not mean here that we should fall prey to the 'Gollum effect' (Higgins 2013), keeping our reo so close to our chests that it languishes until activated in ceremonial settings. After all, Riria used te reo in a humourous, 48 Hour, sci-fi film about dogs that take on human form on Earth. Grant Roa talked about naming a future team 'Concrete Kina', a playful allusion to the urban Māori. Participants also chose Māori character names for their films, for instance Paraone (a transliteration of Brown) in Cold Sunshine (2006). In conversation with Ocean, Rīria agreed that, by contrast, sarcastic or satirical uses of te reo, employed to elicit laughter from a non-Māori audience, felt inappropriate and treated te reo as a toy. This discussion raises the perhaps unanswerable question, what liberties impinge too much on others' freedoms to express their own identities, in this case through language?

\section{People Relationships}

I think it's all about relationships, I think it does come back to a cultural thing. (Richard Tuhaka)

Our participants spoke in numerous ways about the weekend as being 'all about relationships'. Goat Embryo Project operated primarily from the whare mahana on Matiu/Somes island, and began their weekend with a mihimihi session. While this took some time, Terese said it would be 'stink' and 'tedious' going back to working with 'the talented 20-somethings with different ethics' (Terese McLeod).

Grant would set up his production offices 'marae styles' as a place in which sleeping, working and eating together was considered normal. Mattresses and bedding were brought in for everyone. By contrast with the 'all-nighter culture' often expected in 48 Hours, Grant confessed to getting to bed by midnight each night during the competition, and this revealed his priorities that wellbeing and 'play' remained a key kaupapa of their 48. In comparison to other teams he named, his team made their entry with a more relaxed approach to the filming, such as using nearby locations, rather than in multiple sites around town.

Just about all participants mentioned kai, unprompted. Challen Wilson sought sponsorship for kai, recognising its key importance: 'don't be feeding your cast and crew no bread rolls'. Riria felt well looked after by the seemingly magical appearance of water bottles and kai when needed. Grant mentioned that a crockpot of food would always be bubbling away. Indeed, the idea of a slow cooker bleeding edible aromas throughout the weekend was very evocative and prompted a discussion between Grant and Challen of exploring food smell in plays (as in Strange Resting Places) and even films. But as Tyrone and Terese both relayed, good food and its importance are also recognised on non-Māori film sets. As Alice stated, the food not only performs important social (as well as biological) functions, it acknowledges a rhythm and echoes the functioning of a marae.

How participants worked with other Māori revealed kinship: Grant Roa and Emile Taungaroa 'wanted to be dicks together' and Grant called Oscar-winner Keisha CastleHughes in to work on one of his films. Alice and Terese wanted to bring whānau together, 
and Terese wanted Hone Kouka to have involvement in the wider competition. Pele encouraged her students to work together on an entry in te reo. Riria worked with her workmates at Cinco Cine and explained,

Remembering that it was a lot of fun, brought back the memories of "yeah that was really cool and I bet you, none of ya'll out there have done that, aha", you know we were the first ones to do it, woohoo. And so we kinda did it with pride. (Riria Hōtere)

\section{Conclusions and Future Directions}

'The 48' is a constrained space in which participants nonetheless have autonomy over their process. Competitors decide who is involved, what the budget will be, what their story will be and how they'll manage the competition constraints. Story to script to footage to film occurs during a single weekend, with the only checks and balances against what is produced being the constraints of the competition and the constraints of ability and experience. Even then, competitors can flout the rules and still have their film screened. For instance, Taika Waititi's entry Arab Samurai for 2007 was made on location in New York City and submitted 70 hours late. It was ineligible for prizes, but is nonetheless easily found and freely available online. For some of our participants screening was the most rewarding outcome of the weekend.

All teams spoke with pride and satisfaction that they'd completed a film, and achieved other kaupapa besides, whether that was whanaungatanga, increased experience in and/or upskilling in the tikanga of film-making or reflecting and inserting themselves into a wider whakapapa of film. Because of the aforementioned constraints, the end product may have little chance of being festival quality. But as Grant Roa contends, 'the 48' enables other goals, such as discovering and nurturing talent in specific areas, allowing other skills to be developed, in the short space of a weekend.

All our participants agreed that 'the 48' is a fun forum, not to be taken too seriously, and to that end it promotes a freedom to operate. Nonetheless, our participants had much to say about their perceptions of 'the 48' culture, and for instance how their efforts were recognised and rewarded in the space. The competition has shifted by degrees to recognise and encourage diversity, for instance, with the award of a Best Female Director award in Wellington in 2015. If this does not continue and accelerate, the kind of 'freedom' promised by the competition will not be realised for Māori, Pasifika and other minorities. As has been seen before, this may lead to the conditions for creating a new type of contest, as participants have suggested, a Māori 48 Hour Film Contest, in which kaupapa Māori are taken as normal, valued and celebrated. Nonetheless, the range of experiences recounted here demonstrate various expressions of Māori identity that suggested participants, overall, had a rewarding, fun and freeing weekend. 


\section{Acknowledgements}

We would like to mihi to those who have passed, especially Barry Barclay and Merata Mita, and those in our community who continue to work towards a pluralistic model of filmmaking that allows Māori voices and stories to be seen and heard. We gratefully acknowledge our participants. The comments from two anonymous reviewers greatly improved the structure of this article, for which we are grateful. This research was funded by the Faculty of Humanities and Social Sciences, Victoria University of Wellington.

\section{Notes}

${ }^{1}$ Major name sponsors over the years have included (energy drink) V (2007-2012), Rialto (2013-2015) and now Hewlett Packard (2016).

${ }^{2}$ Goat Embryo Project had a diversity of faces in their film: mainly Māori, but also a Samoan, two Pākehā, a British/Italian participant, and even a rodent.

\section{References}

Barclay, Barry. 1990. Our Own Image. Auckland: Longman Paul

Barclay, Barry. 1992. Amongst Landscapes. In Jonathan Dennis and Jan Bieringa. Film in Aotearoa New Zealand. Wellington: Victoria University Press.

Barker, Martin with Thomas Austin. 2000. From Antz to Titanic: Reinventing Film Analysis. London: Pluto Press.

Barnes, Angela Moewaka, Belinda Borell, Ken Taiapa, Jenny Rankine, Ray Nairn and Tim McCreanor. 2012. 'Anti-Māori Themes in New Zealand Journalism - Toward Alternative Practice'. Pacific Journalism Review 18(1): 195-216.

Cunningham, Chris. 2000. 'A Framework for Addressing Maori Knowledge in Research, Science and Technology'. Pacific Health Dialog 7(1): 62-69.

Grant, Catherine. 2008. 'Auteur Machines? Auterism and the DVD'. In Film and Television After DVD, edited by James Bennett and Tom Brown, 101-15. New York: Routledge

Higgins, Rawinia. 2013. 'Comment: Reo Māori Should Define All Nzers'. The Dominion Post, 5 December. http://www.stuff.co.nz/dominionpost/comment/columnists/9478461/Reo-Maori-should-define-all-NZers

Hokowhitu, Brendan. 2012. 'Te Kapa o Taika: A Commentary on Boy'. New Zealand Journal of Media Studies 13(1), 67-72.

Kavka, Misha and Stephen Turner. 2012. 'Boy and the Postcolonial Taniwha'. New Zealand Journal of Media Studies 13(1): 23-28.

Mercier, O. Ripeka. 2014. 'Film Sport: Constraint and Unrestraint in the 48-Hour Film Competition'. New Cinemas: Journal of Contemporary Film 12(3): 191-204. 
Mercier, O. Ripeka and Challen Wilson. 2013. '"Everybody's Putting their Heart and Soul into that One Weekend": Six motivations for entering the 48-hour film competition'. Studies in Australasian Cinema 7(1): 61-76

Mita, Merata. 1992. 'The Soul and the Image'. In Film in Aotearoa New Zealand, edited by Jonathan Dennis and Jan Bieringa, 36-54. Wellington: Victoria University Press.

Reinhard, Carrielynn D. and Christopher J. Olson (eds). 2016. Making Sense of Cinema: Empirical Studies into Film Spectators and Spectatorship. London: Bloomsbury Academic

Roberts, Roma Mere and Peter R. Wills. 1998. 'Understanding Maori Epistemology'. In Tribal Epistemologies: Essays on the Philosophy of Anthropology, edited by Helmut Wautischer, 43-77. Aldershot: Ashgate.

Royal, Te Ahukaramu Charles. 1998. 'Te Ao Mārama: A Research Paradigm'. In Proceedings of Te Oru Rangahau Research and Development Conference. Palmerston North: Te Pūtahi a Toi, Massey University.

Russell, Nicola. 2012. '48hour Film Stars'. Sunday Star Times, 30 April. http://www.stuff.co.nz/entertainment/film/6825199/48hour-film-stars

Smith, Graham Hingangaroa. 1995. 'Whakaoho Whānau: New Formations of Whānau as an Intervention into Māori Cultural and Educational Crises'. He Pūkenga Kōrero: A Journal of Māori Studies 1(1): 18-36.

Smith, Jo. 2012. 'Shaking the Frame: Taika Waititi's Anti-Anthropological Edge'. New Zealand Journal of Media Studies 13(1): 40-46.

Smith, Linda Tuhiwai. 2012. Decolonizing Methodologies: Research and Indigenous Peoples. $2^{\text {nd }}$ Ed. London: Zed Books.

Stephens, Tainui. 2014. 'A Whakapapa of Maori Film'. NZ Studies Network, London, 22 July.

Waititi, Kahurangi. 2008. 'Māori Documentary Film: Interiority and Exteriority'. MAI Review 1(6): 1-10.

Wilson, Jani K. T. 2013. Whiripapa: Tāniko, Whānau and Kōrero-based Film Analysis. Unpublished PhD Thesis. Auckland: University of Auckland. 